\title{
On the extent of fracture toughness transfer from 1D/2D nanomodified epoxy matrices to glass fibre composites
}

\author{
Nadiim Domun ${ }^{1}$, Keith R. Paton ${ }^{2}$, Bamber R. K. Blackman ${ }^{3}$, Cihan Kaboglu ${ }^{3}$, \\ ${ }^{1}$ Department of Mechanical Engineering, Kingston University London, London, UK \\ ${ }^{2}$ National Physical Laboratory, Hampton Road, Teddington, Middlesex, UK \\ ${ }^{3}$ Department of Mechanical Engineering, Imperial College London, London, UK
} Samireh Vahid ${ }^{1}$, Tao Zhang ${ }^{1}$, John P. Dear ${ }^{3}$, Anthony J. Kinloch ${ }^{3}$, and Homayoun Hadavinia ${ }^{1, \star}$ (I)

Received: 30 August 2019

Accepted: 30 December 2019

Published online:

8 January 2020

(C) The Author(s) 2020

\section{ABSTRACT}

In this study, the effects of adding nanofillers to an epoxy resin (EP) used as a matrix in glass fibre-reinforced plastic (GFRP) composites have been investigated. Both 1D and 2D nanofillers were used, specifically (1) carbon nanotubes (CNTs), (2) few-layer graphene nanoplatelets (GNPs), as well as hybrid combinations of (3) CNTs and boron nitride nanosheets, and (4) GNPs and boron nitride nanotubes (BNNTs). Tensile tests have shown improvements in the transverse stiffness normal to the fibre direction of up to about $25 \%$ for the GFRPs using the 'EP + CNT' and the 'EP + BNNT + GNP' matrices, compared to the composites with the unmodified epoxy ('EP'). Mode I and mode II fracture toughness tests were conducted using double cantilever beam (DCB) and end-notched flexure (ENF) tests, respectively. In the quasi-static mode I tests, the values of the initiation interlaminar fracture toughness, $G_{I C}^{C}$, of the GFRP composites showed that the transfer of matrix toughness to the corresponding GFRP composite is greatest for the GFRP composite with the GNPs in the matrix. Here, a coefficient of toughness transfer (CTT), defined as the ratio of mode I initiation interlaminar toughness for the composite to the bulk polymer matrix toughness, of 0.68 was recorded. The highest absolute values of the mode I interlaminar fracture toughness at crack initiation were achieved for the GFRP composites with the epoxy matrix modified with the hybrid combinations of nanofillers. The highest value of the CTT during steady-state crack propagation was $\sim 2$ for all the different types of GFRPs. Fractographic analysis of the composite surfaces from the DCB and ENF specimens showed that failure was by a combination of cohesive (through the matrix) and interfacial (along the fibre/matrix interface) modes, depending on the type of nanofillers used.

Address correspondence to E-mail: h.hadavinia@kingston.ac.uk 


\section{Introduction}

Since the 1980s, various types of fillers have been used by many researchers as a secondary reinforcement for toughening fibre-reinforced polymer (FRP) composites in addition to the primary reinforcing fibres [1-3]. This research has been driven by the fact that the matrices, in many FRPs, are typically based upon a thermosetting epoxy polymer, which has an excellent stiffness and thermal properties, but is a relatively brittle material with a relatively low toughness. These fillers mainly have consisted of relatively soft organic (e.g. rubber or thermoplastic) or inorganic rigid particles, with most recently nanosized filler particles being employed. Indeed, previous studies have shown that the addition of well-dispersed nanofillers in brittle epoxies can simultaneously increase their elastic modulus, tensile strength, ductility and impact resistance [4-6].

The toughening of the polymer matrices used in FRP composites via incorporating nanofillers has advantages over traditional transverse reinforcement methods, such as stitching and Z-pinning [7]. These more traditional methods can cause damage to the fibres, inducing localised stress concentrations, which can reduce the in-plane strength and stiffness of the FRP. Veil and interleaving composites, i.e. incorporating relatively thin thermoplastic polymer films between the laminae, can also reduce the in-plane strength and stiffness in many cases [8]. For example, Kim and Lee [9] reported that, compared to the composite without any inserted interleaved film, the tensile strength, tensile modulus and flexural modulus of the interleaved composites were decreased, although the interlaminar fracture toughness was indeed increased.

The increases in the fracture toughness of thermosetting polymers that have been modified via using nanofillers are due to a combination of the following toughening micromechanisms [1, 4, 10-12]: (1) filler particle/fibre debonding and void nucleation/plastic hole growth in the matrix, (2) localised inelastic matrix deformations, (3) filler particle/fibre pull-out, (4) friction between the filler particle/fibre and matrix during fibre pull-out, (5) filler particle/fibre deformation and possible rupture during pull-out, (6) crack path deflection and (7) crack pinning. Now, the type and volume fraction of filler particles, their size and shape, and the degree of interfacial bonding all play important roles in influencing the extent of these toughening micromechanisms in a given polymer nanocomposite. Further, when such polymer nanocomposites are used as the matrices for fibre-reinforced plastic (FRP) composites, it has been shown [13, 14] not only that the nanofillers can improve the mode I fracture toughness, $G_{\mathrm{IC}}^{\mathrm{m}}$, of the polymer matrix but that commensurate increases in the modes I and II interlaminar fracture toughnesses, $G_{\mathrm{IC}}^{\mathrm{C}}$ and $G_{\mathrm{IIC}}^{\mathrm{C}}$, respectively, of the FRP composite may be observed.

Now, of direct relevance to the above discussion is the fact that the general problem of matrix-to-composite toughness transfer has been studied by many previous researchers, e.g. Compston et al. [15, 16], Bradley [17, 18] and Jordan et al. [19], especially via a comparison of the values of $G_{\mathrm{IC}}^{\mathrm{m}}$ and $G_{\mathrm{IC}}^{\mathrm{C}}$. For example, Compston et al. [16] reported that, in brittle matrix composites, the toughness is fully transferred at crack initiation. On the other hand, in FRP composites with relatively tough matrices a poor transfer of the toughness from the matrix to the composite was observed which was attributed to the constraint effects of the long, relatively rigid reinforcing fibres which were effectively sandwiched between the thin resin-rich regions. This effect may greatly restrict the volume of the crack tip plastic deformation zone in the matrix resin and so limits the development of any active toughening micromechanisms, and hence limits the toughness transfer. However, the energy absorbed by the formation and fracture of the bridging reinforcing fibres has an enhancing effect on the toughness, whereby the value of $G_{\mathrm{IC}}^{\mathrm{C}}$ for steadystate crack propagation became greater than $G_{\mathrm{IC}}^{\mathrm{m}}$ $[20,21]$. Thus, the improvement in the value of $G_{I C}^{C}$ for the FRP compared to any improvement in the value of $G_{\mathrm{IC}}^{\mathrm{m}}$ of the matrix due to the addition of nanofillers depends on the type of nanofiller, the type and size of the primary fibres used and the architecture of the primary fibre reinforcement.

A parameter that can be used to quantify the toughness transfer between the matrix and composite is the coefficient of toughness transfer (CTT), which may be defined as [15]:

$\mathrm{CTT}=\frac{G_{\mathrm{IC}}^{\mathrm{C}}}{G_{\mathrm{IC}}^{\mathrm{m}}}$

Now, there are reports on the values of the CTT from the matrix to the corresponding FRP composite in the literature, but the overall picture is somewhat 
confusing. For example, Bradley [17] reported that for a brittle matrix the observation that $G_{\mathrm{IC}}^{\mathrm{C}}>G_{\mathrm{IC}}^{\mathrm{m}}$ may be attributed to (1) an increased fracture area created in the matrix by crack propagation, (2) the effect of fibre bridging and (3) the slower rate of decay of the stress field ahead of the crack tip in the FRP. Further, strong interfacial bonding also promoted cohesive failure in the matrix. Further, Zeng et al. [22] showed that for a $12 \mathrm{wt} \%$ nanorubber loading in an epoxy matrix, the interlaminar toughness of a carbon fibre-reinforced plastic (CFRP) composite was less than $50 \%$ of the bulk epoxy matrix toughness, i.e. giving a CTT $<0.5$. However, values of the CTT of 1.0 have also been reported [23] for $4 \mathrm{wt} \%$ of nanosilica filler particles in an anhydride-cured epoxy polymer with respect to a CFRP composite. Also, values of CTT of 5.5 were found for $10 \mathrm{wt} \%$ of nanosilica filler particles in a similar anhydride-cured epoxy polymer employed as the matrix for an unidirectional (UD) GFRP composite [24]. On the other hand, hybrid combinations of nanosilica/rubber filler particles in an epoxy have been reported [23] to give a CTT of only 0.5 for $8 \mathrm{wt} \%$ nanosilica/4 wt $\%$ nanorubber filler particles for a CFRP composite using biaxially aligned carbon fibres. A CTT of 2.0 was found for $10 \mathrm{wt} \%$ nanosilica/9 wt \% microrubber filler particles in an epoxy for a GFRP composite using biaxially aligned glass fibres [25]. The CTT for a $5 \mathrm{wt} \%$ nanoclay-modified epoxy has been reported to be 0.3 with respect to a CFRP composite with UD carbon fibres [26] and 1.2 for a CFRP composite with woven carbon fibres [27]. Finally, the CTT for $0.1 \mathrm{wt} \%$ single-walled carbon nanotubes (CNTs) in an epoxy polymer was determined to be 1.0 for a CFRP composite with UD carbon fibres [28], but a value of the CTT of 3.4 was recorded for $0.5 \mathrm{wt} \%$ of multi-walled CNTs in an epoxy for a CFRP composite using a biaxial noncrimp carbon fabric [29]. From the above comments, the extent of the bulk matrix toughness transfer to the interlaminar fracture toughness of the corresponding FRP composite using different nanofillers in the matrix clearly requires further investigation to better understand the controlling factors.

In the present work, four different types of nanofillers were used for modifying an epoxy to form bulk epoxy polymer nanocomposites, and these epoxy nanocomposites were then employed as matrices for GFRP composites. The nanofillers employed were GNPs, CNTs, hybrid CNTs/BNNS and hybrid
GNPs/BNNTs, where GNPs are graphene nanoplatelets, BNNS are boron nitride nanosheets and BNNTs are boron nitride nanotubes. We have specifically selected this range of both $1 \mathrm{D}$ and $2 \mathrm{D}$ nanofillers to give the possibility of formulating epoxies containing a hybrid combination of $1 D+2 D$ nanofillers. The 1D nanofillers are in the form of nanofibres, nanorods or nanotubes, such as the CNTs and BNNTs. On the other hand, the 2D nanofillers are layered materials in the form of single or multiple layers of sheets of GNPs and BNNS. Therefore, bulk epoxy polymer nanocomposites [30] and GFRP composites using such nanomodified epoxies as the matrix have been made, where the nanofillers have been used individually to give a 1D or 2D nanofiller, or as hybrids where a combination of a $1 D+2 D$ nanofillers was used. Subsequently, the effects of these nanofillers on the tensile properties of the composites were investigated. Next, quasi-static mode I double cantilever beam (DCB) and mode II end-notched flexure (ENF) delamination tests were conducted, and the extent of transfer of the mode I matrix toughness, $G_{\mathrm{IC}}^{\mathrm{m}}$, of the bulk epoxy polymer nanocomposites to the interlaminar fracture toughnesses of the corresponding GFRP composites under both mode I, $G_{\mathrm{IC}}^{\mathrm{C}}$, and mode II loadings, $G_{\mathrm{IIC}}^{\mathrm{C}}$, has been assessed. Finally, fractographic analyses of the delamination surfaces from the DCB and ENF GFRP specimens have been carried out to identify the micromechanisms responsible for any improvements in the interlaminar toughnesses of the GFRP composites due to the presence of the nanofillers in the epoxy matrix.

\section{Materials and specimen manufacture}

\section{Materials}

The resin used in this study was a two-part lowviscosity epoxy, Araldite ${ }^{\circledR}$ LY 564 resin and a cycloaliphatic polyamine Aradur ${ }^{\circledR} 2954$ hardener, both supplied by Huntsman, UK. The recommended ratio of resin to hardener of 100:35 by weight was used, giving a gel time of approximately $90 \mathrm{~min}$ at $60^{\circ} \mathrm{C}$. The glass transition temperature, $\mathrm{Tg}$, of the unmodified epoxy was measured using dynamic mechanical analysis (DMA) and was $161 \pm 0.3^{\circ} \mathrm{C}$. The measured values of $\mathrm{Tg}$ for all the GNP-, CNT- 
and both hybrid-modified epoxies were reported in $[30,31]$.

Figure 1 shows scanning electron microscopy (SEM) images of the four types of nanofillers used in this research, confirming the expected morphology of each nanofiller type. The GNPs had undergone a proprietary plasma process to surface treat the platelets and were supplied by Haydale Ltd (HDPlas ${ }^{\circledR}$ GNP-O ${ }_{2}-\mathrm{STD}$, Batch Number: 8039). They were used without further modification. The multi-walled carbon nanotubes NC3100 were purchased from Nanocyl SA (Sambreville, Belgium). These had been produced by a catalytic chemical vapour deposition (CVD) process. The average diameter of the carbon nanotubes was given by the supplier as $\sim 9.5 \mathrm{~nm}$ with an average length of $1.5 \mu \mathrm{m}$ and a carbon purity of $>95.0 \%$. Analytical-grade $\mathrm{HNO}_{3}$, methanol and ethanol, used for the surface treatment of the CNTs, were obtained from Sigma-Aldrich (Poole, UK). The functionalised multi-walled carbon nanotubes (simply termed CNTs hereafter) were prepared following a procedure described previously [30]. Briefly, the unmodified multi-walled carbon nanotubes $(0.1 \mathrm{~g})$ were dispersed in $100 \mathrm{ml}$ of $\mathrm{HNO}_{3}(70 \%)$ in a roundbottomed flask $(250 \mathrm{~mL})$ equipped with a condenser and refluxed at $135{ }^{\circ} \mathrm{C}$ for $24 \mathrm{~h}$. Next, the mixture was diluted in deionised (DI) water $(18.2 \mathrm{M} \Omega \mathrm{cm}$ ) and filtered with a Millipore ${ }^{\mathrm{TM}}$ Isopore filter membrane (Millipore, Watford, UK). The collected solid was then repeatedly washed with DI water, methanol and ethanol until a neutral $\mathrm{pH}$ was reached. The CNTs were subsequently dried in a vacuum oven at $40{ }^{\circ} \mathrm{C}$. Multi-walled boron nitride nanotubes (BNNTs) were purchased from NAiEEL Technology (Daejeon, South Korea) and had an average diameter of $100 \mathrm{~nm}$ with a length $>1 \mu \mathrm{m}$ and were used as-received. The hexagonal boron nitride powder (h-BN) was purchased from UK Abrasives, Inc. (Northbrook, IL, USA). Functionalized boron nitride nanosheets (BNNSs) were prepared by a heat treatment of the hexagonal boron nitride in air. In a typical experimental run, $20 \mathrm{~g}$ of $\mathrm{h}-\mathrm{BN}$ powder was placed in a quartz tube in a tube furnace. The furnace was heated to $1000{ }^{\circ} \mathrm{C}$ and held at that temperature for $2 \mathrm{~h}$ in air, and then, the h-BN was washed with hot water to yield the BNNSs.

A unidirectional E-glass fibre fabric, with a weight of $254 \mathrm{~g} \mathrm{~m}^{-2}$ ( $\left.\pm 5 \%\right)$ and 600 tex, was used for this study and was purchased from Marineware Ltd (Eastleigh, UK).

\section{Manufacture of the composites}

The epoxy polymer nanocomposites were produced using the procedures described in detail in [30]. The nanofiller material was dispersed by sonication in
Figure 1 SEM images of the nanofillers used in the epoxy polymer nanocomposites: a CNTs; b GNPs; c BNNSs; and d BNNTs [30].

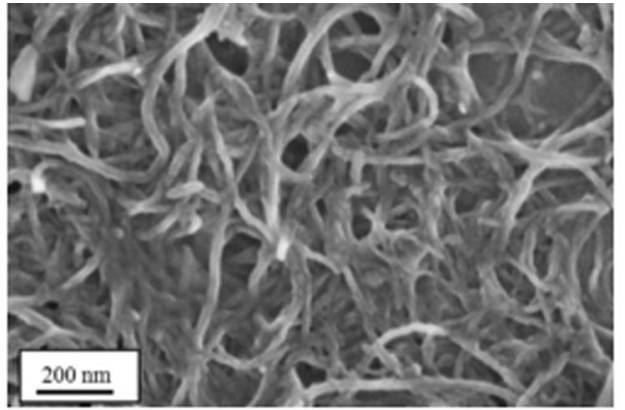

(a)

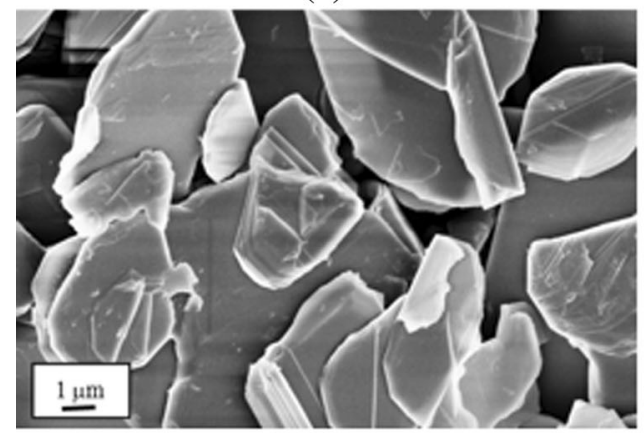

(c)

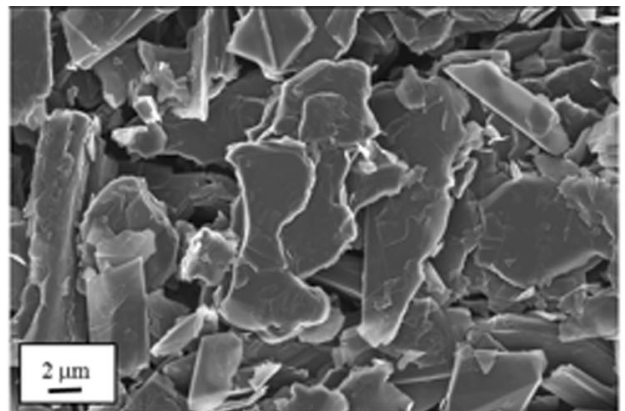

(b)

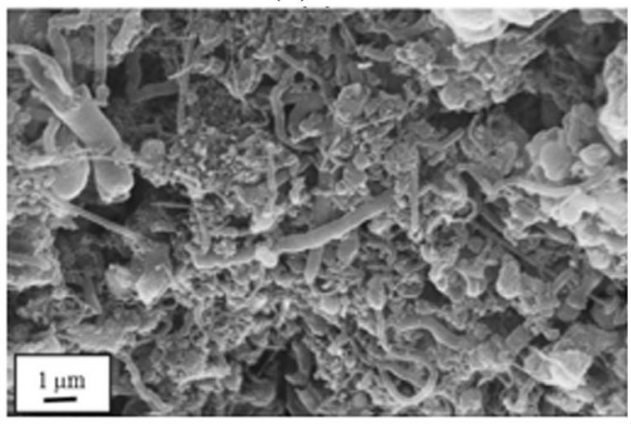

(d) 
methanol, and then, the epoxy resin was added dropwise, stirring continuously. The methanol was then removed in a rotary evaporator. A high-speed mixer was then employed to mix the epoxy nanocomposite. The hardener was then added to the resin/filler mixture, which was mixed again using a high-speed mixer. The final epoxy nanocomposite resins were obtained by degassing the product under vacuum. In previous studies, the optimum values of the concentrations of the GNP and CNT nanoparticles for achieving maximum toughness of the epoxy nanocomposites were determined [30, 31]. The optimum concentration was $0.25 \mathrm{wt} \%$ for the GNPs and $0.1 \mathrm{wt} \%$ for the CNTs. Therefore, four nanomodified epoxies containing (1) $0.25 \mathrm{wt} \%$ of GNPs, (2) $0.1 \mathrm{wt} \%$ of CNTs, (3) $0.1: 0.1 \mathrm{wt} \%$ of CNTs:BNNSs and (4) 0.25:0.1 wt $\%$ of GNPs:BNNTs were produced using the above method. A control matrix of the neat, unmodified epoxy ('EP') was also employed. Such epoxy formulations were either prepared in the form of cured sheets to give bulk epoxy polymer nanocomposites or used as the matrix to manufacture GFRP composites, as described below. The formulations are termed: 'neat epoxy $(\mathrm{EP})^{\prime}$, 'EP + $\mathrm{GNP}^{\prime}$, 'EP + $\mathrm{CNT}^{\prime}, \quad$ 'EP + BNNS + CNT' and ${ }^{\prime} \mathrm{EP}+\mathrm{BNNT}+\mathrm{GNP}^{\prime}$.

The GFRP composites were manufactured using a vacuum bagging hand lay-up process with the various unmodified and nanomodified epoxies as the matrix. The glass fibre plies were cut and stacked in the required orientations (see Table 1; Figs. 7 and 8), and a roller was used to fully wet the glass fibre fabric by the matrix epoxy resin. A polyester peel ply, perforated film and non-woven polyester/polyamide breather cloth were then applied. A nylon vacuum bagging film was employed to seal the composite, and a gum sealant tape was used for sealing the vacuum bags, as shown in Fig. 2 . A vacuum valve was inserted in the bagging film and connected to a vacuum pump, and a vacuum of $\sim 1$ atmospheric pressure was applied. The GFRP sheets were heated to $80^{\circ} \mathrm{C}$ and left for $1 \mathrm{~h}$, followed by $160^{\circ} \mathrm{C}$ for $4 \mathrm{~h}$, to cure the epoxy resin. The resulting FRP with an

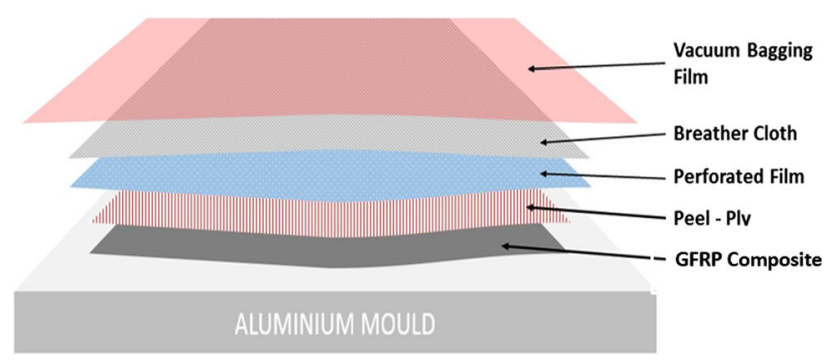

Figure 2 Hand lay-up-assisted vacuum bagging technique.

epoxy nanocomposite matrix, or the unmodified epoxy matrix, was then cooled down to room temperature (RT) at a constant rate of $3{ }^{\circ} \mathrm{C}$ per minute. From both a visual inspection and the SEM studies, there appeared to be no significant concentration of air voids in the GFRP sheets. Further, the latter studies indicated that there appeared to be no orientation of the nanofillers in the epoxy matrix.

\section{Materials characterisation}

\section{Tensile and shear tests}

The tensile properties of the GFRP composites were measured according to ASTM D3039 [32] for the inplane properties at $0^{\circ}$ and $90^{\circ}$ fibre directions. ASTM D3518 [33] was followed to measure the in-plane shear response by the tensile testing of $\pm 45^{\circ}$ GFRP composites. Aluminium end tabs were bonded onto the ends of the specimens using an epoxy adhesive (Scotch-Weld DP410, 3 M USA) to improve the gripping of the specimen during testing, with the end tabs having a low bevel angle of about $10^{\circ}$. Two strain gauges (supplied by Micro-Measurement Co., UK), with a grid resistance of $120.0 \pm 0.3 \% \Omega$, were attached at the centre of the specimens: one in the axial direction and the other in the transverse direction. The details of the GFRP specimens tested at the $0^{\circ}, 90^{\circ}$ and $\pm 45^{\circ}$ fibre directions are shown in Fig. 3 and Table 1. The crosshead speed used was $2 \mathrm{~mm} \mathrm{~min}{ }^{-1}$. A $100 \mathrm{kN}$ load cell was used for the $0^{\circ}$ fibre direction specimens, and a $50 \mathrm{kN}$ load cell was
Table 1 Nominal dimensions of the GFRP specimens used for the $0^{\circ}$ and $90^{\circ}$ fibre direction tensile tests and the $\pm 45^{\circ}$ fibre direction shear tests

\begin{tabular}{llllll}
\hline Type of the test & Lay-up & $L(\mathrm{~mm})$ & $W(\mathrm{~mm})$ & $L_{\text {tab }}(\mathrm{mm})$ & $t(\mathrm{~mm})$ \\
\hline Longitudinal tensile test & {$\left[0^{\circ}\right]_{20}$} & 250 & 25 & 56 & 3.3 \\
Transverse tensile test & {$\left[90^{\circ}\right]_{20}$} & 175 & 25 & 25 & 3.3 \\
Shear test & {$\left[ \pm 45^{\circ}\right]_{10}$} & 250 & 25 & 56 & 3.3 \\
\hline
\end{tabular}




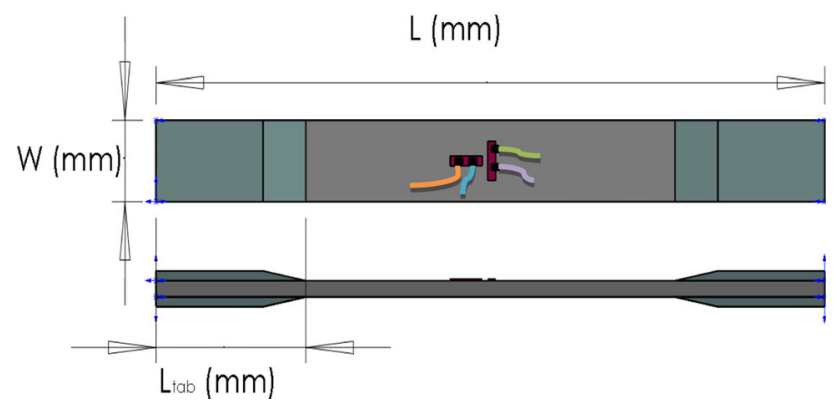

Figure 3 Geometry of the specimen for the $0^{\circ}, 90^{\circ}$ fibre direction tensile and $\pm 45^{\circ}$ fibre direction shear tests with the two strain gauges attached. The nominal thickness for all the specimens was $t=3.3 \mathrm{~mm}$.

used for all other tests. For each case, five replicate samples were tested.

\section{Results of tensile and shear tests}

Typical results for the tensile stress-strain curves for the $0^{\circ}$ and $90^{\circ}$ fibre directions of the GFRP composites and the shear stress-shear strain curve for the $\pm 45^{\circ}$ fibre direction GFRP composites are shown in Figs. 4, 5 and 6 . The values of the mean values from the replicate specimens with a $95 \%$ confidence level at $\pm 1.960 \sigma_{\bar{x}}$ (where $\sigma_{\bar{x}}=\frac{\sigma}{\sqrt{N}}$ and $\sigma$ is the standard deviation and $\mathrm{N}$ is the number of specimens) for the tensile and shear properties of the various GFRP composites are given in Table 2. Values are shown for the longitudinal elastic modulus, $E_{1}$, transverse elastic modulus, $E_{2}$, shear modulus, $G_{12}$, Poisson's ratio,

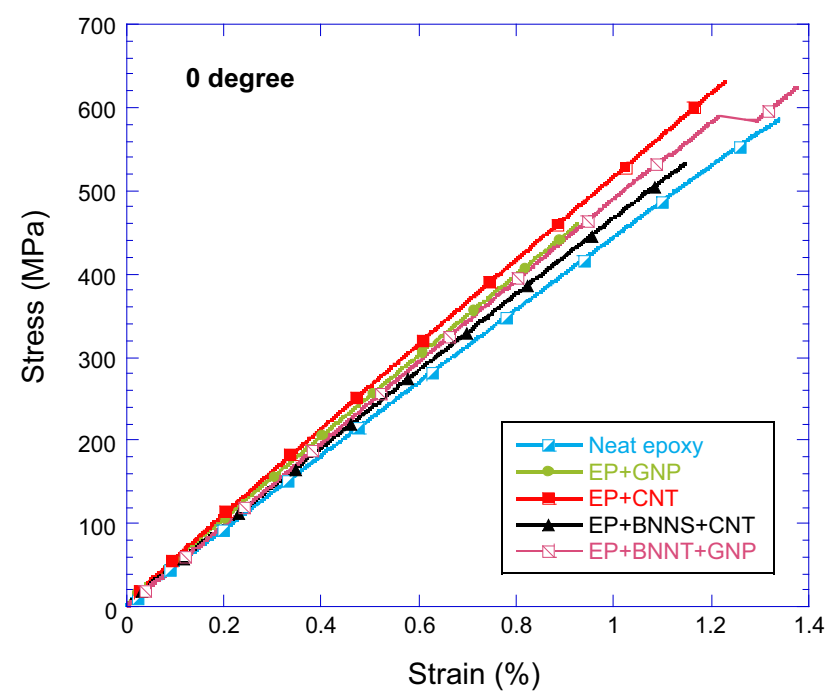

Figure 4 Typical results of tensile tests for the GFRP composites for the $0^{\circ}$ fibre direction with the various epoxy matrices.

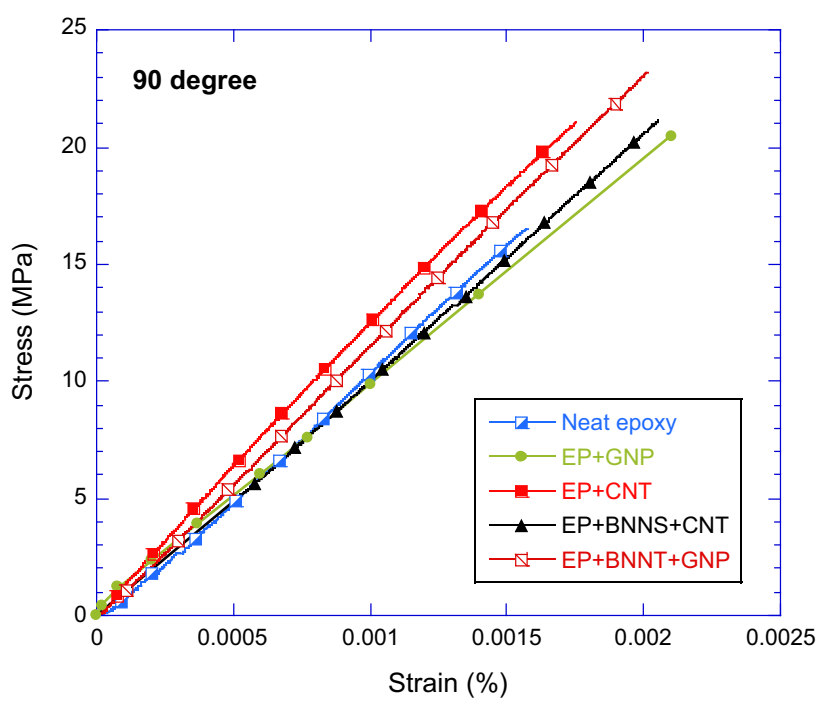

Figure 5 Typical results of tensile tests for the GFRP composites for the $90^{\circ}$ fibre direction with the various epoxy matrices.

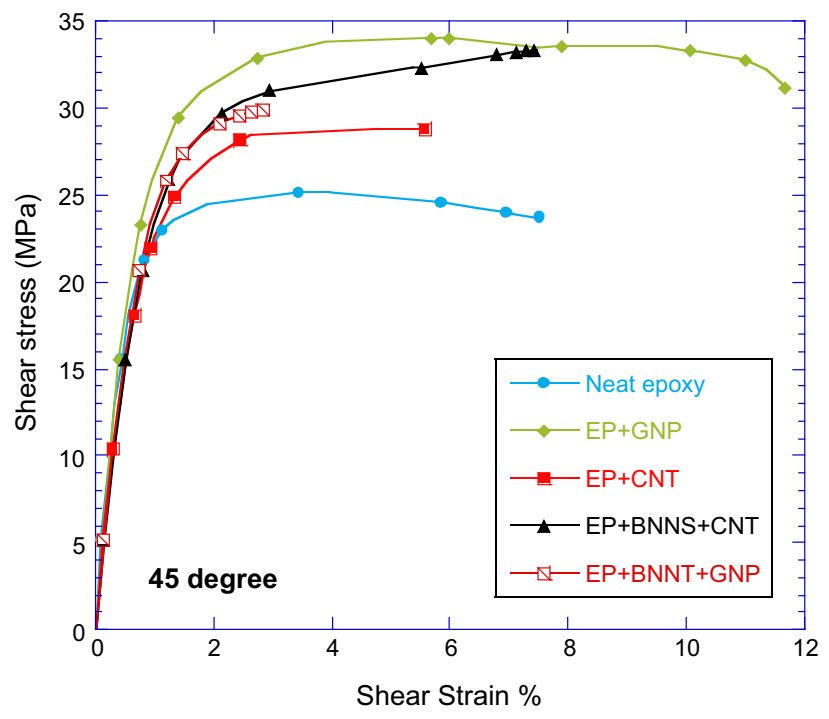

Figure 6 Typical results of in-plane shear tests for the GFRP composites for the $\pm 45^{\circ}$ fibre direction with the various epoxy matrices.

$v_{12}$, tensile strength in the fibre direction, $X_{t}$, transverse tensile strength normal to the fibre direction, $Y_{t}$, and shear strength, $S$. The average fibre volume fractions, $V_{\mathrm{f}}$, for the GFRP composites using the four different types of epoxy nanocomposite and the unmodified epoxy matrices were measured from burn-off tests, and the values of $V_{\mathrm{f}}$ are also reported. As may be seen, there is no significant difference in the values of $V_{\mathrm{f}}$ for the various GFRP composites

The longitudinal elastic modulus, $E_{1}$, of the GFRP composite is dominated by the presence of the glass 
Table 2 Mechanical properties for the GFRP composites with various epoxy matrices

\begin{tabular}{lcccccccc}
\hline Matrix & $V_{\mathrm{f}} \%$ & \multicolumn{1}{c}{$E_{1}(\mathrm{GPa})$} & \multicolumn{1}{c}{$E_{2}(\mathrm{GPa})$} & $G_{12}(\mathrm{GPa})$ & $v_{12}$ & $X_{t}(\mathrm{MPa})$ & $Y_{t}(\mathrm{MPa})$ & $S(\mathrm{MPa})$ \\
\hline Neat epoxy (EP) & 65.8 & $43.6 \pm 0.9$ & $10.8 \pm 0.6$ & 3.72 & 0.264 & $570 \pm 12$ & $16.7 \pm 3.5$ & $28.4 \pm 1.9$ \\
EP + GNP & 68.4 & $52.2 \pm 3.8$ & $8.3 \pm 1.4$ & 4.73 & 0.261 & $493 \pm 37$ & $18.3 \pm 3.2$ & $33.7 \pm 0.7$ \\
EP + CNT & 64.7 & $48.3 \pm 4.2$ & $13.6 \pm 1.2$ & 3.93 & 0.266 & $565 \pm 49$ & $21.5 \pm 1.2$ & $29.3 \pm 2.7$ \\
EP + BNNS + CNT & 65.6 & $43.6 \pm 4.1$ & $11.6 \pm 1.5$ & 3.47 & 0.265 & $533 \pm 22$ & $18.8 \pm 2.3$ & $31.1 \pm 1.3$ \\
EP + BNNT + GNP & 67.3 & $47.9 \pm 0.8$ & $13.6 \pm 2.9$ & 3.72 & 0.263 & $576 \pm 49$ & $19.0 \pm 5.7$ & $29.5 \pm 0.5$ \\
\hline
\end{tabular}

fibres and the contribution of the matrix is minimal, as indeed would be expected. (The somewhat higher value of $E_{1}$ for the GFRP composite using the 'EP + $\mathrm{GNP}^{\prime}$ matrix is most likely to arise, at least in part, from the slightly higher value of $V_{\mathrm{f}}$ for this GFRP composite.) On the other hand, the effect of the elastic modulus of the matrix on the transverse elastic modulus, $E_{2}$, of the GFRP composite is more noticeable. Indeed, incorporation of nanofillers into the epoxy matrix may increase somewhat the value of the $E_{2}$ modulus of the GFRP composite when using the ' $\mathrm{EP}+\mathrm{CNT}^{\prime}$ and the 'EP + BNNT + GNP' matrices, with an increase of about $25 \%$ being recorded for these GFRP composites, compared to using the neat epoxy $\left({ }^{\prime} \mathrm{EP}^{\prime}\right)$. In the case of the tensile strength in the fibre direction, $X_{t}$, the transverse tensile strength normal to the fibre direction, $Y_{t}$, and the shear strength, $S$, there are no significant differences in the values of the various GFRP composites.

\section{Mode I and mode II delamination tests}

\section{Mode I interlaminar fracture toughness using the double cantilever beam (DCB) specimen}

The mode I interlaminar fracture toughness, $G_{\mathrm{IC}}^{\mathrm{C}}$, of the GFRP composites using the various matrices was determined using double cantilever beam (DCB) specimens according to the ISO 15024 standard [34]. The dimensions of the DCB specimen are given in Fig. 7. Unidirectional plies of glass fibres were used to manufacture the DCB specimens with a lay-up of $[0]_{32}$, with the $0^{\circ}$ fibre direction aligned with the longitudinal direction of the DCB specimen. A precrack was inserted in the DCB specimens by placing a PTFE film of about $12.5 \mu \mathrm{m}$ in thickness in the midplane of the specimen to initiate the delamination. The pre-crack length was $55 \mathrm{~mm}$ in length from the end of the specimen. A thin layer of white paint was

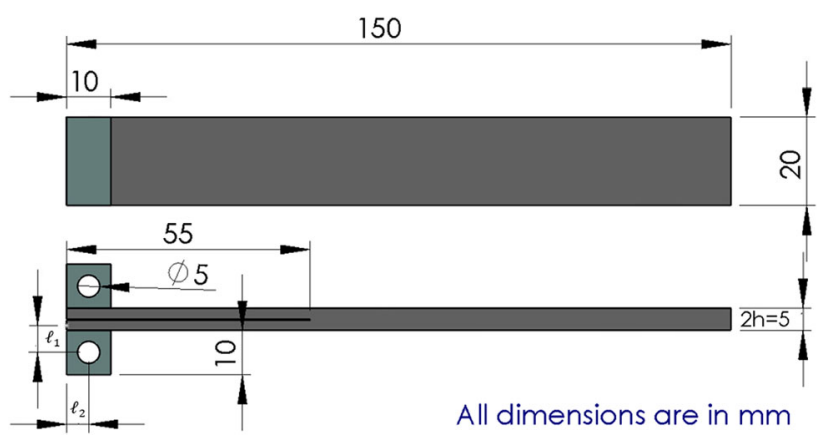

Figure 7 Dimensions of the mode I double cantilever beam (DCB) test specimen made from unidirectional GFRP with a layup of $[0]_{32}$.

applied to one edge of the specimen, and this edge was marked at $1 \mathrm{~mm}$ intervals for the first $5 \mathrm{~mm}$ ahead of the PTFE insert and then every $5 \mathrm{~mm}$ to the end of the DCB specimen. This allowed the crack length to be identified and measured as the crack propagated. Steel end blocks were bonded onto the specimen using the DP410 $3 \mathrm{M}$ Scotch-Weld epoxy adhesive at the pre-cracked end. The tests were performed under standard laboratory conditions of $23 \pm 3{ }^{\circ} \mathrm{C}$ and a relative humidity of $42 \%$ using a Zwick Z250 tensile machine. The crosshead speed was $5 \mathrm{~mm} \mathrm{~min}^{-1}$, and a $50 \mathrm{kN}$ load cell was employed. Load versus displacement data were recorded for each individual crack length measurement. Further, during the tests, the crack length was measured, using a travelling microscope, as the crack propagated through the DCB test specimen. Five replicate specimens were tested for statistical evaluation. The initiation point on the load versus displacement diagram for calculating $G_{\mathrm{IC}}^{\mathrm{C}}$ was taken by drawing a best straight line to determine the initial compliance, $C_{0}$, ignoring any initial deviation due to take-up in the loading system. Next, a new line was drawn with a compliance equal to $C_{0}+5 \%$ whose intersection with the load versus displacement curve 
yielded the load and displacement to be used for the calculation of initiation $G_{\mathrm{IC}}^{\mathrm{C}}$, unless the intersection was at a larger displacement than the maximum load in which case the maximum load and the corresponding displacement were used [34].

The mode I interlaminar fracture toughness, $G_{\mathrm{IC}}^{\mathrm{C}}$, for the initiation of the crack was calculated using the 'corrected beam theory (CBT)' method [35-37] from:

$G_{\mathrm{IC}}^{\mathrm{C}}=\frac{3 P \delta}{2 b(a+|\Delta|)} \cdot \frac{F}{N}$

where $P$ is the critical load necessary to extend the crack, $\delta$ is the load-line displacement, $a$ is the crack length and $b$ is the beam width. The term $\Delta$ is the crack length correction to allow for crack tip rotation at the root of the cantilever beam and was found from the intersect on the $\mathrm{x}$-axis of a plot of $C^{1 / 3}$ versus crack length, $a$, where the compliance $C=\delta / P$. The correction factors $F$ and $N$ for the shortening of the moment arm and load block stiffening of the beam can be determined from the following equations [38]:

$F=1-\frac{3}{10}\left(\frac{\delta}{a}\right)^{2}-\frac{3}{2}\left(\frac{\delta \ell_{1}}{a^{2}}\right)$

$N=1-\left(\frac{\ell_{2}}{a}\right)^{3}-\frac{9}{8}\left[1-\left(\frac{\ell_{2}}{a}\right)^{2}\right] \frac{\delta \ell_{1}}{a^{2}}-\frac{9}{35}\left(\frac{\delta}{a}\right)^{2}$

where $\ell_{1}$ is the distance from the centre of the loading pin to the mid-plane of the arm to which the load block is bonded and $\ell_{2}$ is the distance from the loading pin centre to the edge of the block (see Fig. 7).

\section{Mode II interlaminar fracture toughness using the end- notched flexure (ENF) specimen}

The three-point loaded, end-notched flexure (ENF) test was carried out to evaluate the mode II interlaminar fracture toughness, $G_{\mathrm{IIC}}^{\mathrm{C}}$, of the GFRP composites made with the different epoxy matrices. The ENF geometry, dimensions and test set-up are shown in Fig. 8. Unidirectional plies were used to manufacture ENF specimens with a lay-up of $[0]_{32}$ where the fibres were laid along the length of the beam. In the ENF test, the load was applied at a constant displacement rate of $1.6 \mathrm{~mm} \mathrm{~min}{ }^{-1}$, the delamination length, $a$, from the pre-crack was monitored during crack propagation. Data for the crack length, load and displacement were captured during crack propagation to calculate the $G_{\text {IIC }}^{\mathrm{C}}$ values. The crack initiation was defined by a $5 \%$ increase in the initial compliance, $C_{0}$, or by the maximum load point, as was explained previously for the DCB test.

The calculation of the interlaminar fracture toughness, $G_{I I C}^{C}$, from the ENF tests was performed according to the 'corrected beam theory with effective crack length (CBTE)' method [39]. The effective crack length, $a_{\mathrm{e}}$, was calculated from:

$a_{\mathrm{e}}=\sqrt[3]{\frac{8 E_{1} b h^{3} C_{\mathrm{c}}}{3}-\frac{2 L^{3}}{3}}$

where $C_{\mathrm{c}}=C_{\mathrm{m}}-\frac{3 L}{10 \mathrm{G}_{12} b h^{\prime}}$, the measured experimental compliance, $C_{\mathrm{m}}=\frac{\delta}{p}$, and the apparent longitudinal modulus, $E_{1}$, was found from:

$E_{1}=\frac{8 a_{0}^{3}+2 L^{3}}{8 b h^{3} C_{\mathrm{m} 0}}$

where $a_{0}$ is the initial crack length, $C_{\mathrm{m} 0}$ is the measured initial compliance and the half span length $L=50 \mathrm{~mm}$.

The mode II interlaminar fracture toughness, $G_{\text {IIC }}^{\mathrm{C}}$ can then be found from:

$G_{\text {IIC }}^{\mathrm{C}}=\frac{9 P^{2} a_{\mathrm{e}}^{2}}{16 b^{2} E_{1} h^{3}}$

The parameter $h$ is half the beam thickness, as shown in Fig. 8. The meaning of the remaining parameters is as before.

\section{Results of the mode I and mode II toughness tests}

\section{Mode I double cantilever beam (DCB) test results}

The DCB test set-up is illustrated in Fig. 9a, and typical load versus displacement curves for the GFRP using the control, neat epoxy ('EP') matrix and the four epoxy nanocomposite matrices are shown in Fig. 10a. A 'stick-slip' type of crack growth occurred for all the GFRP composites using matrices of the various epoxy nanocomposites. Hine et al. [40] have reported that such unstable crack propagation in FRP composites is caused by local regions of high toughness. Thus, when the crack tip reaches a tougher region (for example, due either to a somewhat tougher region of the matrix or to fibre bridging having developed), crack propagation is retarded until the build-up of stored elastic energy becomes sufficient to reinitiate crack propagation [41]. However, upon reinitiation, the stored elastic energy is typically higher than required for stable propagation 
Figure 8 Dimensions of the mode II end-notched flexure (ENF) test specimen made from unidirectional GFRP with a lay-up of $[0]_{32}$.

Figure 9 DCB fracture evaluation: a test configuration, $\mathbf{b}$ crack propagation during the $\mathrm{DCB}$ test and $\mathbf{c}$ fibre bridging observed during the crack propagation.

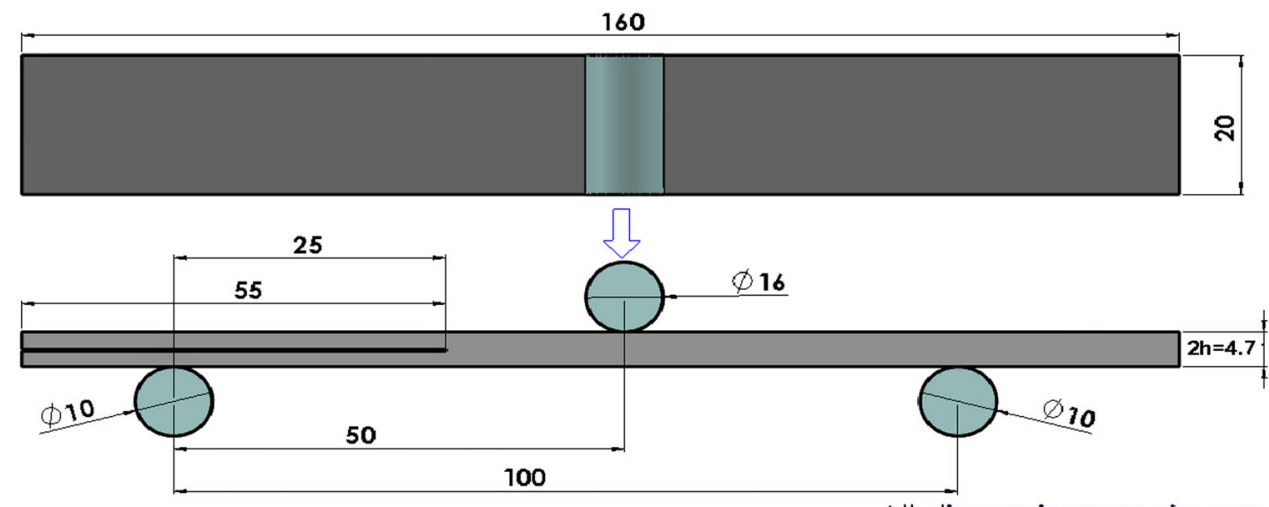

All dimensions are in $\mathrm{mm}$
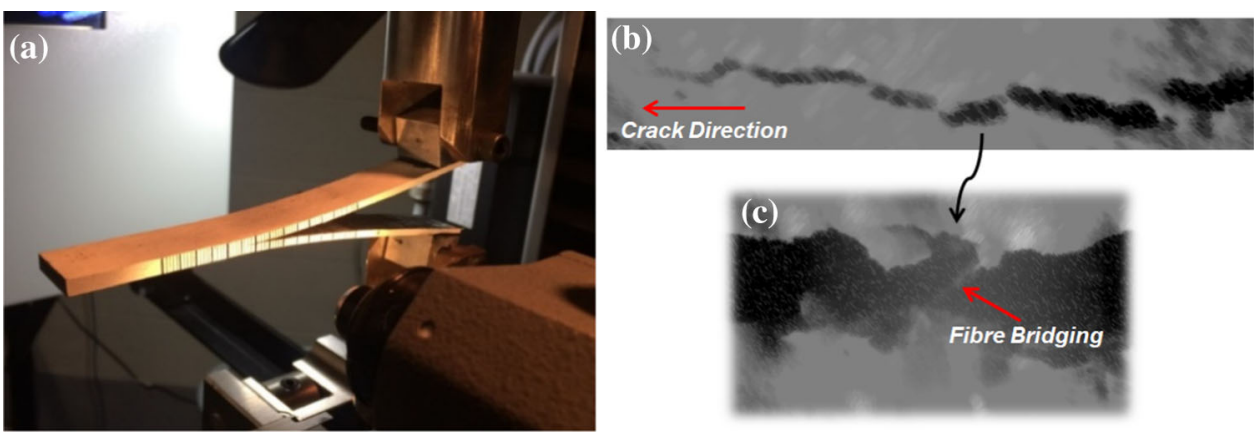

and the crack now propagates very rapidly in an unstable manner until it runs out of sufficient input energy for further growth and arrests. Other factors such as crack blunting and resharpening and an imbalance between the static and dynamic toughnesses also contribute to stick-slip crack growth. Indeed, fibre bridging was observed during crack growth, as depicted in Fig. 9b, c.

The calculated mean values of the mode I interlaminar fracture toughness at crack initiation are summarised in Table 3 and are shown in Fig. 10b, along with the respective $95 \%$ confidence levels of $\pm 1.960 \sigma_{\bar{x}}$. Further, the values of the mode I fracture toughness of the bulk epoxy polymers were reported in [30] and [31], and the results are summarised in Table 3. Considering the values of the initiation interlaminar fracture toughness for the GFRP composites, then from these results, firstly for the bulk epoxy polymer, the results in Table 3 reveal that a mean value of $G_{\mathrm{IC}}^{\mathrm{m}}=162 \pm 24 \mathrm{~J} \mathrm{~m}^{-2}$ was measured for the unmodified bulk epoxy polymer ('EP') and that this epoxy is most effectively toughened by using the hybrid combination of 'BNNT + GNP' nanofillers to give a value of $G_{\mathrm{IC}}^{\mathrm{m}}=311 \pm 37 \mathrm{~J} \mathrm{~m}^{-2}$. Secondly, turning to the GFRP composites with the hybrid combinations of $1 \mathrm{D}+2 \mathrm{D}$ nanofiller matrices, it may be seen that these GFRP composites possess relatively high values of $G_{\mathrm{IC}}^{\mathrm{C}}=181 \pm 48 \mathrm{~J} \mathrm{~m}^{-2}$ for crack initiation for the 'EP + BNNS + $\mathrm{CNT}^{\prime}$ matrix and $G_{\mathrm{IC}}^{\mathrm{C}}=176 \pm 18 \mathrm{~J} \mathrm{~m}^{-2}$ for the 'EP $+\mathrm{BNNT}+$ $\mathrm{GNP}^{\prime}$ matrix. Indeed, the delamination resistance of both the hybrid matrix GFRP composites is notably higher than for the GFRP composite with the unmodified epoxy matrix ('EP'), where $G_{\mathrm{IC}}^{\mathrm{C}}=113 \pm 23 \mathrm{~J} \mathrm{~m}^{-2}$. Indeed, the increases in toughness are about $60 \%$ and $56 \%$, respectively, with respect to the GFRP composites made using the hybrid-modified epoxy matrices. Next, in Table 3 the values of the propagation toughnesses at a crack length of $85 \mathrm{~mm}$, where the R-curve becomes relatively stable, are also shown for the GFRP composites. The values of $G_{I C}^{C}$ for steady-state crack propagation in the GFRP composites are significantly greater than for crack initiation, as expected, and the relatively high values of $G_{\text {IC }}^{C}$ for steady-state crack propagation in the GFRP composites made using the epoxy nanocomposite matrices are especially noteworthy. This former observation is considered to arise mainly from the fibre bridging that occurs during crack propagation, as shown in Fig. 9b, c. It is noteworthy that for the crack initiation toughness 


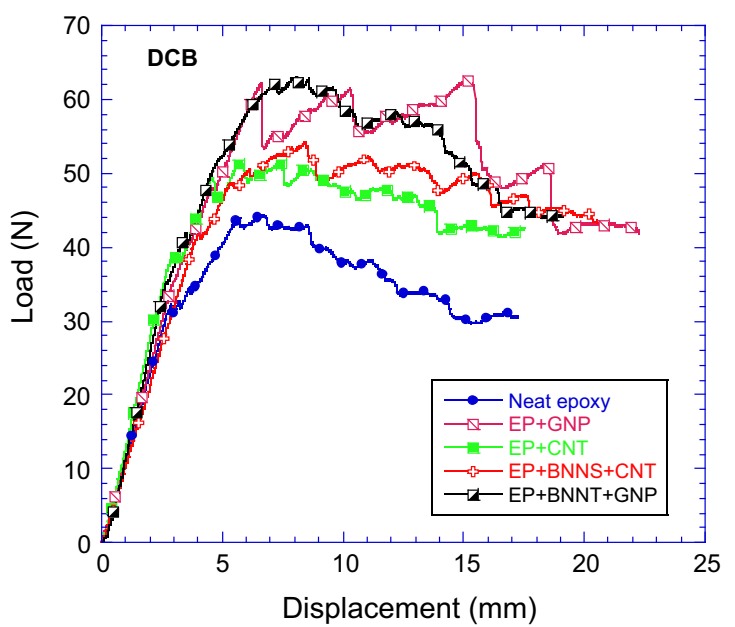

(a)

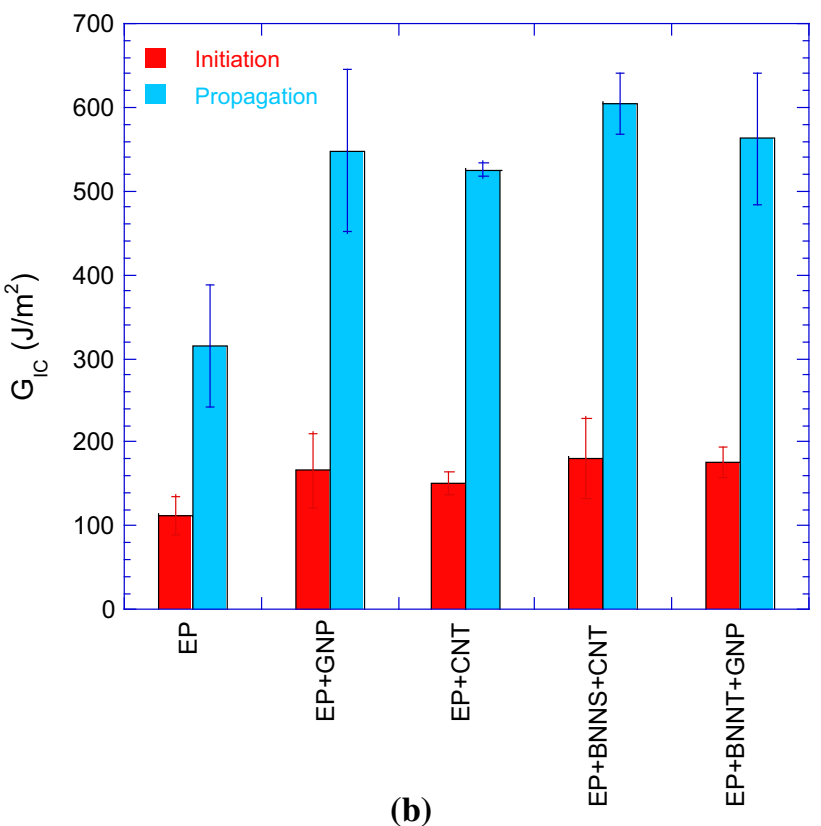

Figure 10 DCB test results for the GFRP composites using the unmodified epoxy matrix and the various epoxy nanocomposite matrices: a typical load versus displacement curves and $\mathbf{b}$ mean values of the mode I interlaminar fracture toughness, $G_{\mathrm{IC}}^{\mathrm{C}}$, for crack initiation and steady-state propagation.

data the values of CTT were always less than 1 . However, for crack propagation, values of CTT $=2$ were achieved for all the GFRP composites.

\section{Mode II end-notched flexure (ENF) test results}

Figure 11 illustrates the end-notched flexure (ENF) test where a travelling microscope was again employed to examine the crack tip. However, the data reduction technique used an 'effective crack length approach', so any uncertainty about the crack tip position did not affect the results. Figure 12a shows examples of the load versus displacement curves from the ENF tests for the GFRP composite using the neat epoxy ('EP') matrix and the four epoxy polymer nanocomposite matrices. The results for $G_{\text {IIC }}^{\mathrm{C}}$ for all the tests are shown in Fig. 12b and are summarised in Table 4. As expected, the values of $G_{\text {IIC }}^{\mathrm{C}}$ are significantly greater in value than those of $G_{I C}^{C}$..

The mode II interlaminar fracture toughness, $G_{\text {IIC }}^{\mathrm{C}}$, for all the GFRP composites with the nanomodified epoxies increased relative to the GFRP with the unmodified epoxy matrix ('EP'). The $G_{I I C}^{C}$ for the GFRP with the neat epoxy ('EP') matrix had a value of $568 \pm 59 \mathrm{~J} \mathrm{~m}^{-2}$. A statistically significant increase in the $G_{\text {IIC }}^{C}$ for the GFRP composites is observed for all the four nanocomposite matrices relative to the GFRP with the neat epoxy matrix. The percentage increases in the values of $\mathrm{G}_{\mathrm{IIC}}^{\mathrm{C}}$ are about $49 \%, 58 \%, 37 \%$ and $42 \%$ for the 'EP + GNP', 'EP + CNT', 'EP + $\mathrm{BNNS}+\mathrm{CNT}^{\prime}$ and 'EP + BNNT + GNP' matrices, respectively.

\section{Values of the coefficient of toughness transfer (CTT) from the bulk matrices to the GFRP composites}

For crack initiation, the values of the coefficient of toughness transfer (CTT) from the bulk polymers to the corresponding GFRP composites for the different matrices are summarised in Table 3 for the mode I data. The highest value of the CTT was obtained for the unmodified, neat epoxy ('EP'). For the epoxy nanocomposites, the 'EP $+\mathrm{GNP}^{\prime}$ material has the highest value of $\mathrm{CTT}=0.68$. However, there is no real significant difference in these values of CTT. Further, as noted above, the GFRP composite with the hybrid ' $\mathrm{EP}+\mathrm{BNNS}+\mathrm{CNT}^{\prime}$ matrix had a somewhat lower value of CTT of 0.65 , but gave the maximum value of $G_{\mathrm{IC}}^{\mathrm{C}}=181 \pm 48 \mathrm{~J} \mathrm{~m}^{-2}$. These results show the transfer of toughness from the matrix, $G_{\mathrm{IC}}^{\mathrm{m}}$, to the initiation interlaminar fracture toughness, $G_{\text {IC }}^{C}$, of the GFRP composite is always less than unity. This arises from the constraint imposed on the matrix deformation at the crack tip by the presence of the fibres in the GFRP composite, which restricts the development of the matrix deformation zone, and hence energy dissipation, in these relatively tough GFRP composites which employed the epoxy nanocomposites as matrices. In the case of 
Table 3 Comparison of the values of the mode I bulk toughness, $G_{\mathrm{IC}}^{\mathrm{m}}$, of the epoxy polymers compared to the initiation and steady-state propagation mode I interlaminar fracture toughnesses, $G_{\mathrm{IC}}^{\mathrm{C}}$, of the corresponding GFRP composites based upon the various epoxy matrices

\begin{tabular}{|c|c|c|c|c|c|c|c|c|}
\hline \multirow[t]{2}{*}{ Type of matrix } & \multicolumn{2}{|c|}{$\begin{array}{l}\text { Mode I fracture toughness for the } \\
\text { bulk polymer }\end{array}$} & \multicolumn{3}{|c|}{$\begin{array}{l}\text { Initiation interlaminar fracture } \\
\text { toughness of the GFRP }\end{array}$} & \multicolumn{3}{|c|}{$\begin{array}{l}\text { Propagation interlaminar fracture } \\
\text { toughness of the GFRP }\end{array}$} \\
\hline & $G_{\mathrm{IC}}^{\mathrm{m}}\left(\mathrm{J} \mathrm{m}^{-2}\right)$ & $\begin{array}{l}\% \text { increase } \\
\text { relative to } \\
\text { neat epoxy }\end{array}$ & $G_{\mathrm{IC}}^{\mathrm{C}}\left(\mathrm{J} \mathrm{m}^{-2}\right)$ & $\begin{array}{l}\% \text { increase } \\
\text { relative to } \\
\text { neat epoxy }\end{array}$ & CTT & $G_{\mathrm{IC}}^{\mathrm{C}}\left(\mathrm{J} \mathrm{m}^{-2}\right)$ & $\begin{array}{l}\% \text { increase } \\
\text { relative to } \\
\text { neat epoxy }\end{array}$ & CTT \\
\hline Neat epoxy (EP) & $162 \pm 24[31]$ & - & $113 \pm 23$ & - & 0.70 & $315 \pm 73$ & - & 1.9 \\
\hline $\mathrm{EP}+\mathrm{GNP}$ & $245 \pm 36[31]$ & 51.2 & $166 \pm 45$ & 47 & 0.68 & $548 \pm 97$ & 70 & 2.2 \\
\hline $\mathrm{EP}+\mathrm{CNT}$ & $255 \pm 26[30]$ & 57.4 & $151 \pm 14$ & 34 & 0.59 & $526 \pm 10$ & 63 & 2.1 \\
\hline $\mathrm{EP}+\mathrm{BNNS}+\mathrm{CNT}$ & $278 \pm 35[30]$ & 71.6 & $181 \pm 48$ & 60 & 0.65 & $605 \pm 36$ & 87 & 2.2 \\
\hline $\mathrm{EP}+\mathrm{BNNT}+\mathrm{GNP}$ & $311 \pm 37[30]$ & 92.0 & $176 \pm 18$ & 56 & 0.57 & $563 \pm 78$ & 74 & 1.8 \\
\hline
\end{tabular}

Values of the coefficient of toughness transfer (CTT) from the bulk polymers to the GFRP composites are also given

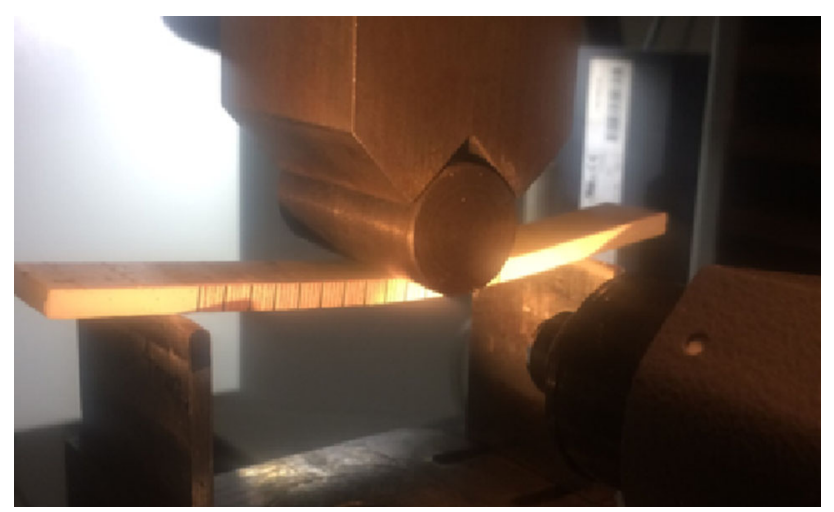

Figure 11 ENF test set-up with a scale ruler marked face. A travelling microscope was again used for measuring the crack length.

steady-state crack propagation, then values of CTT $=1.8-2.2$ have been achieved for all the various epoxy polymer matrices used in the different GFRP composites. These relatively high values of CTT are considered to be mainly due to fibre bridging occurring during crack propagation in the GFRP composites; see Fig. 9b, c.

\section{Fractographic analyses of the DCB and ENF test specimens}

Fractographic analysis of the fracture surfaces of the DCB and ENF specimens was carried out to identify the toughening mechanisms. All the analyses of the fracture surface were performed using a LEO, Gemini 1525 field emission gun scanning electron microscope (FEGSEM), operated at an accelerating voltage of $5 \mathrm{kV}$ and controlled by ZEISS software. The samples cut from the DCB and ENF delaminated fractured areas in the propagation region were coated with $15 \mathrm{~nm}$ of chromium using a sputter coater (Q150T, Quorum Technologies, UK) to prevent charging from such non-conductive samples.

The SEM images for all the various matrices used for the GFRP composites from the mode I DCB tests in the propagation region are shown in Fig. 13. The FEGSEM image for the GFRP delamination fracture surface using the neat epoxy matrix $\left({ }^{\prime} \mathrm{EP}^{\prime}\right)$ is presented in Fig. 13a and is generally smooth and featureless with no visible debris. Further, the fibres are completely devoid of any retained matrix, indicating that failure occurred along the fibre/matrix interface which resulted in a relatively low value of $G_{\mathrm{IC}}^{\mathrm{C}}$. The surface of the composite using the 'EP + GNP'modified matrix (Fig. 13b) shows a higher degree of roughness which is indicative of matrix plastic deformation. Figure $13 \mathrm{~b}$ also clearly shows that some cohesive failure has occurred within the matrix, and so, a higher toughness would be expected. Indeed, the propagation $G_{\mathrm{IC}}^{\mathrm{C}}$ for this 'EP + GNP' composite is $548 \pm 97 \mathrm{~J} \mathrm{~m}^{-2}$, compared to $315 \pm 73 \mathrm{~J} \mathrm{~m}^{-2}$ for the composite with the neat epoxy matrix ('EP'). Figure $13 \mathrm{c}$ shows the fracture surface of the GFRP composite using the CNT-modified epoxy matrix, with the CNTs attached to the fibres where they have been pulled out from the matrix. Again, a higher delamination toughness would be expected relative to the neat epoxy ('EP') GFRP, as is indeed observed. Figure $13 \mathrm{~d}$ shows a FEGSEM image of the GFRP composites using the epoxy matrix with the hybrid combination of $1 \mathrm{D}+2 \mathrm{D}$ ' $\mathrm{EP}+\mathrm{BNNS}+\mathrm{CNT}^{\prime}$ nanofillers. The presence of the nanofillers within the 


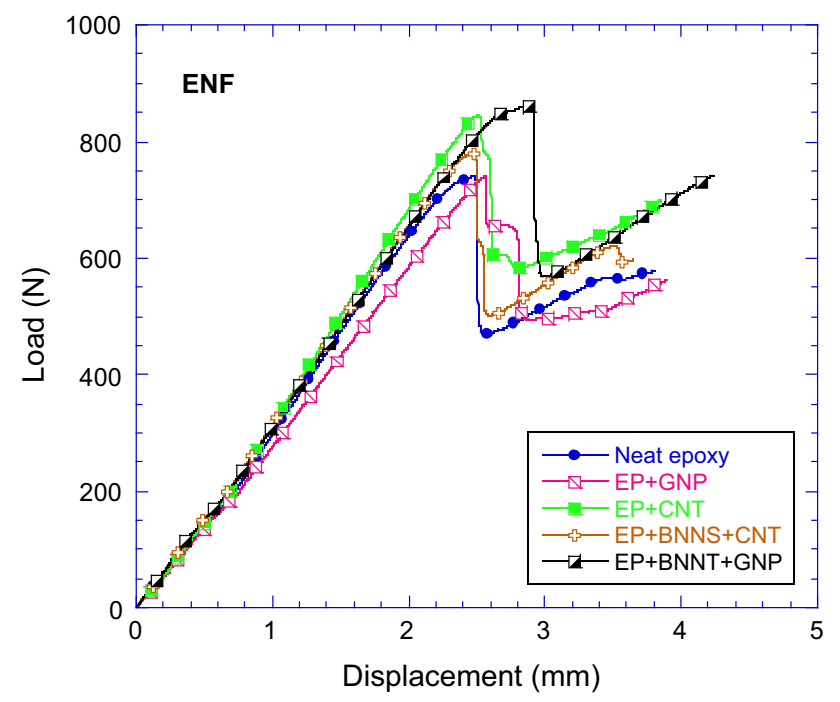

(a)

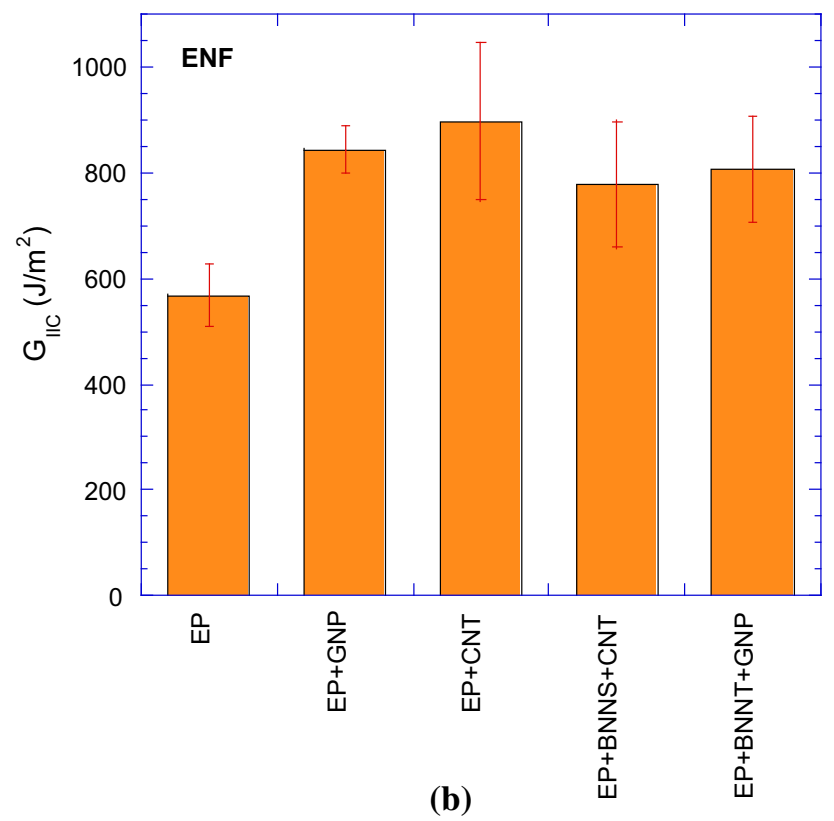

Figure 12 ENF test results for the GFRP composite using the unmodified epoxy matrix and various epoxy polymer nanocomposite matrices: a typical load versus displacement curves and $\mathbf{b}$ mean values of the mode II interlaminar fracture toughness, $G_{\text {IIC }}^{\mathrm{C}}$, at crack initiation. epoxy matrix that are attached to the fibres is evident, which increases the fibre surface roughness and the fracture surface area. As a result, the frictional work for fibre pull-out and surface energy expenditure for creating the fracture surface increases, and consequently, the interlaminar fracture toughness of the hybrid 1D + 2D 'EP + BNNS + CNT' GFRP will increase upon crack propagation. This phenomenon is also evident in Fig. 13e for the hybrid 'EP + BNNT + GNP' GFRP composite. For this matrix, the fibres are also partly covered with retained nanocomposite matrix, again indicating a significant degree of cohesive failure through the matrix. Therefore, for both hybrid systems, there is a greater utilisation of the matrix toughness, and this is reflected in the somewhat higher values of $G_{I C}^{C}$ for steady-state crack propagation compared to the other epoxy polymer matrices that were employed.

The FEGSEM images for the fracture surfaces for the GFRP composites from the mode II ENF test specimens are shown in Fig. 14. The FEGSEM image for the neat epoxy matrix ('EP') from the mode II test is shown in Fig. 14a and reveals the typical features of brittle fracture in composite materials upon mode II delamination, with a small extent of shear hackles present. Under mode II loading, matrix microcracking, shear deformation in the zone ahead of the crack tip and ductile tearing of the matrix ligaments are major energy absorbing micromechanisms. These microcracks are responsible for the creation of the hackle mark features shown in Fig. 14. Such microcracks result in a more tortuous crack propagation path than in mode I, creating a much higher fracture surface area, resulting in the value of $G_{\mathrm{C}}^{\mathrm{C}}$ under mode II loading being significantly higher than for mode I loading. The fracture surface of the GFRP composite with the 'EP + GNP' matrix under mode II loading (Fig. 14b) shows a relatively high degree of plastic deformation of the matrix with a much higher extent
Table 4 Values of the initiation mode II interlaminar fracture toughness, $G_{\text {IIC }}^{C}$, for the GFRP composites with the various epoxy matrices

\begin{tabular}{lll}
\hline Type of matrix & \multicolumn{2}{l}{ Mode II initiation interlaminar fracture toughness of the GFRP } \\
\cline { 2 - 3 } & $G_{\text {IIC }}^{\text {C }}\left(\mathrm{J} \mathrm{m}^{-2}\right)$ & $\%$ increase relative to neat epoxy \\
\hline Neat epoxy (EP) & $568 \pm 59$ & - \\
EP + GNP & $844 \pm 45$ & 49 \\
EP + CNT & $897 \pm 149$ & 58 \\
EP + BNNS + CNT & $778 \pm 120$ & 37 \\
EP + BNNT + GNP & $806 \pm 100$ & 42 \\
\hline
\end{tabular}


Figure 13 FEGSEM images of the fracture surfaces in the steady-state propagation region of the mode I DCB GFRP specimens. The matrices employed were: a the neat (i.e. unmodified) epoxy ('EP'), $\mathbf{b}$ the 'EP + GNP', c the 'EP + CNT', $\mathbf{d}$ the hybrid ' $\mathrm{EP}+\mathrm{BNNS}+\mathrm{CNT}$ ' and $\mathbf{e}$ the hybrid 'EP + BNNT + GNP'.
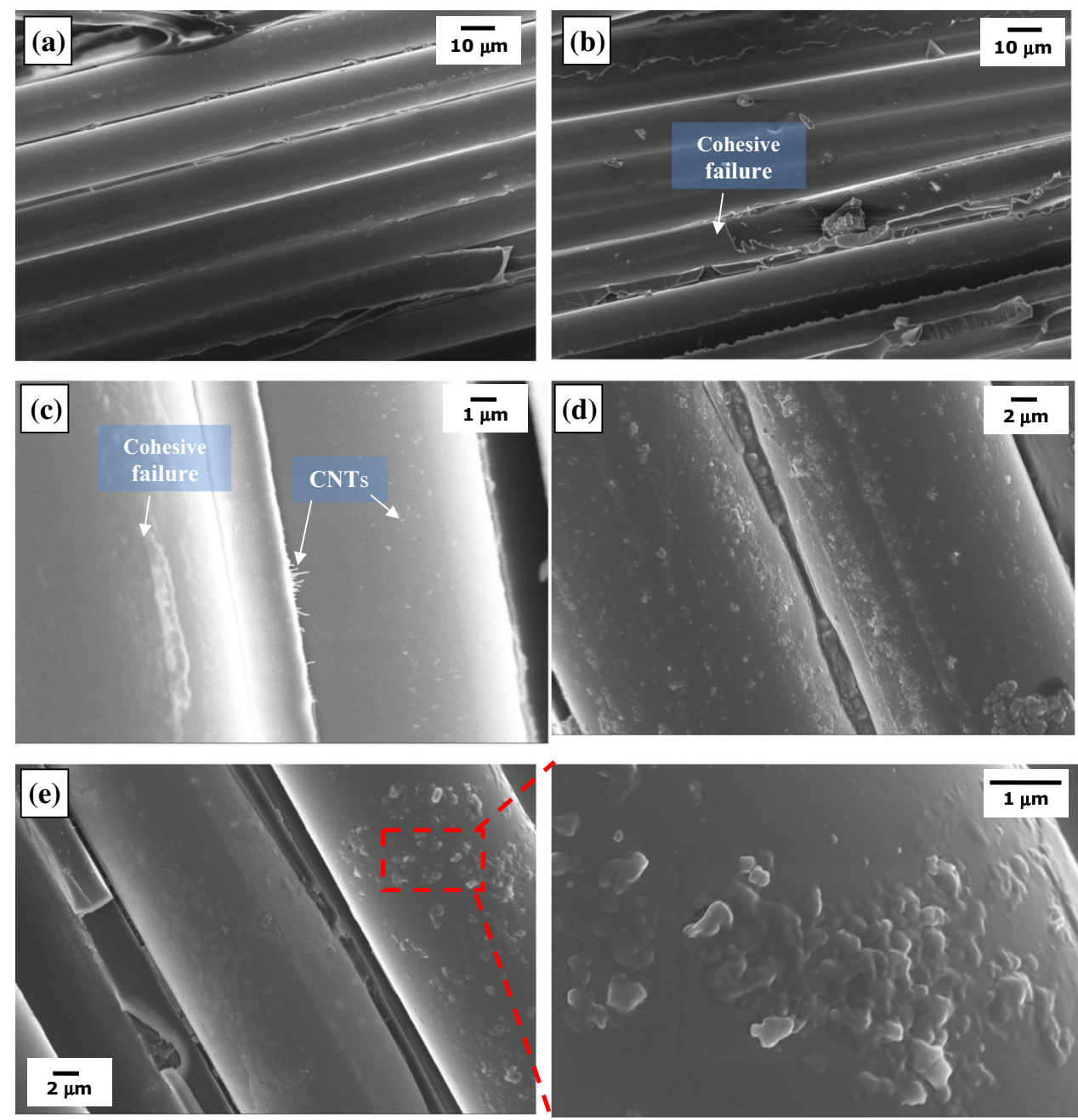

of shear hackles, relative to the GFRP composite using the neat epoxy matrix ('EP'). A similar fracture surface is observed for the GFRP composite using the 'EP + CNT' matrix under mode II loading (Fig. 14c), underlying the presence of extensive plastic deformation resulting in the maximum values of $G_{\text {IIC }}^{C}$ that were recorded; see Fig. $12 \mathrm{~b}$ and Table 4 . The FEGSEM image of the GFRP using the epoxy matrix modified with the hybrid combination of 'EP + BNNS $+\mathrm{CNT}^{\prime}$ nanofillers is shown in Fig. 14d. A lower degree of shear hackles on the fracture surface relative to the GFRP using the 'EP + CNT' epoxy may be observed. Indeed, the value of $G_{\text {IIC }}^{C}$ is lower for the GFRP composite using the hybrid 'EP + $\mathrm{BNNS}+\mathrm{CNT}^{\prime}$ matrix compared to the GFRP composite using the 'EP $+\mathrm{CNT}^{\prime}$ matrix. A similar pattern of behaviour exists for the GFRP using the hybrid 'EP + BNNT + GNP' matrix, as may be seen from comparing Fig. 14c, e.
Effects of using the hybrid combinations of 1D and 2D nanofillers

Considering firstly the results for the mechanical properties of the various GFRP composites, as shown in Table 2, then clearly there is no benefit from using the hybrid combinations of $1 \mathrm{D}$ and 2D nanofillers in the epoxy matrices for the GFRP composites, compared to simply using the GNP or CNT nanofillers by themselves. Hence, the results for the hybrid 'EP + $\mathrm{BNNS}+\mathrm{CNT}^{\prime}$ and 'EP + BNNT + GNP' GFRP composites are not significantly greater in value than for the GFRP composites with only the GNP or CNT nanofillers present in the matrix.

Secondly, considering the mode I fracture toughness results, see Table 3 and Fig. 10b, then using hybrid combinations of 1D and 2D nanofillers for the bulk epoxy polymer nanocomposites does lead to the highest mean values of $G_{\mathrm{IC}}^{\mathrm{m}}$. Furthermore, the 
Figure 14 FEGSEM images of the fracture surfaces in the propagation region of the mode II ENF GFRP specimens. The matrices employed were: a the neat (i.e. unmodified) epoxy (EP), $\mathbf{b}$ the 'EP + GNP', $c$ the 'EP + CNT', $\mathbf{d}$ the hybrid 'EP + BNNS + CNT' and e the hybrid 'EP + BNNT + GNP'.
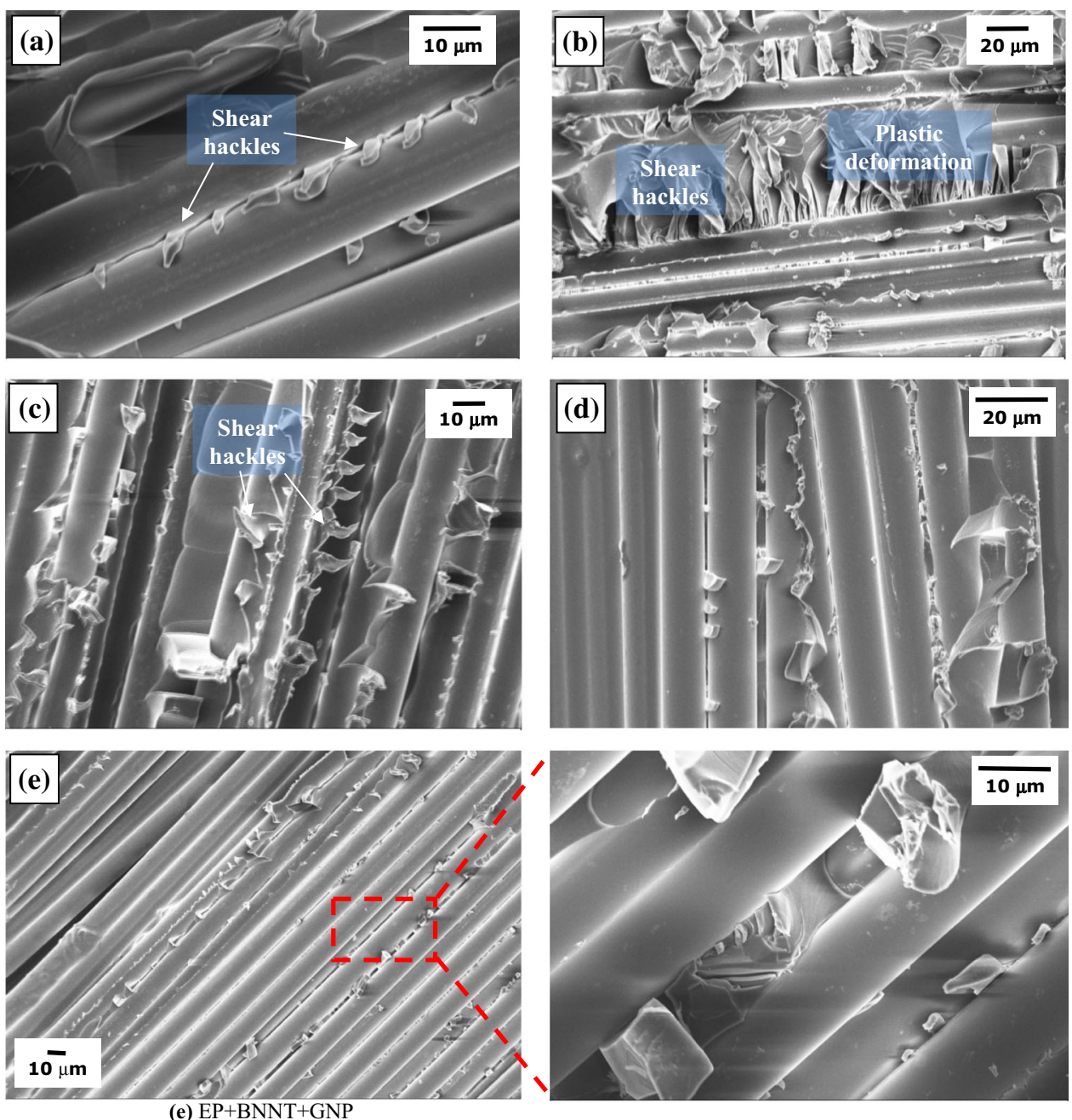

relatively high values of $G_{\mathrm{IC}}^{\mathrm{m}}$ for these epoxy nanocomposite matrices are transferred to the corresponding GFRP composites. This is clearly revealed by the respective values of CTT which are very similar for the different GFRP composites, in the case of the values of interlaminar toughness both for the onset of crack initiation and for steady-state crack propagation. However, whilst the hybrid combinations of nanofillers clearly result in relatively high mean values of toughness compared to the neat, control ('EP') bulk epoxy polymer and the 'EP' GFRP composite, there are no real significant differences in the values of $G_{\mathrm{IC}}^{\mathrm{m}}$ and $G_{\mathrm{IC}}^{\mathrm{C}}$ between the various types, or combinations, of nanofillers that were employed in the various matrices.

Thirdly, for the mode II values, see Table 4 and Fig. 12b, all the nanofillers when present in the matrix give higher values of $G_{\text {IIC }}^{\mathrm{C}}$ than was measured for the 'EP' GFRP composite. However, the hybrid combinations of 1D and 2D nanofillers do not lead to the highest mean values of $G_{\mathrm{IIC}}^{\mathrm{C}}$, although the relatively high values of the standard deviations associated with the mean values of $G_{\text {IIC }}^{C}$ prevent any definitive conclusions being drawn as to which nanofillers in the epoxy nanocomposite matrix are the most effective in increasing the value of $G_{\text {IIC }}^{C}$ for the GFRP composites.

Finally, it should be noted that the above results provide no evidence for any synergistic toughness effects being present from using these hybrid combinations of 1D and 2D nanofillers compared to using the individual CNT and GNP nanofillers separately in the bulk epoxy polymers or in the matrices for the GFRP composites, as is most clearly seen from the results as presented in Table 3, Figs. 10b and $12 \mathrm{~b}$. 


\section{Conclusions}

In the present research, GNPs, CNTs and hybrid combinations of BNNS + CNTs and of BNNT + GNP, nanofillers were used to modify a bulk epoxy polymer. Corresponding GFRP composites were also made using these nanocomposite epoxies [and the unmodified, neat epoxy ('EP')] as the matrices. The tensile properties and the mode I and mode II interlaminar fracture toughnesses of these GFRP composites were characterised. The values of the coefficient of toughness transfer (CTT) from the bulk epoxy nanocomposite to the GFRP composites were determined through a comparison of the initiation values of $G_{\mathrm{IC}}^{\mathrm{m}}$ of the bulk epoxy polymer with the initiation and propagation values of $G_{\mathrm{IC}}^{\mathrm{C}}$ of the corresponding GFRP composites.

The incorporation of the nanofillers into the epoxy matrix had a significant effect on the value of $E_{2}$ of the GFRP composite when using the 'EP + $\mathrm{CNT}^{\prime}$ and the 'EP + BNNT + GNP' matrices, with an increase of about $25 \%$ being recorded for these GFRP composites, compared to the GFRP with the neat epoxy matrix ('EP'). The longitudinal elastic modulus, $E_{1}$, of the GFRP composite was dominated by the presence of the glass fibres, and the effect of the matrix employed was not significant. Also, in the case of the tensile strength in the fibre direction, $X_{t}$, the transverse tensile strength normal to the fibre direction, $Y_{t}$, and the shear strength, $S$, there were no significant differences in these strength values of the GFRP composites as the epoxy matrix was modified by the addition of the nanofillers.

For the mode I fracture tests, for the bulk epoxy materials the results firstly revealed that the mean value of $G_{\mathrm{IC}}^{\mathrm{m}}$ for the unmodified, bulk epoxy was $162 \pm 24 \mathrm{~J} \mathrm{~m}^{-2}$ and that this epoxy was most effectively toughened by using the hybrid combination of 'BNNT + GNP' nanofillers to give a mean value of $G_{\mathrm{IC}}^{\mathrm{m}}=311 \pm 37 \mathrm{~J} \mathrm{~m}^{-2}$. Secondly, turning to the GFRP composite with the hybrid combinations of $1 \mathrm{D}+2 \mathrm{D}$ nanofiller matrices, then these composites possessed the highest mode I interlaminar fracture toughness at crack initiation with $G_{\mathrm{IC}}^{\mathrm{C}}=181 \pm 48 \mathrm{~J} \mathrm{~m}^{-2}$ for the ${ }^{\prime} \mathrm{EP}+\mathrm{BNNS}+\mathrm{CNT}^{\prime}$ matrix and $G_{\mathrm{IC}}^{\mathrm{C}}=178 \pm 18 \mathrm{~J} \mathrm{~m}^{-2}$ for the 'EP $+\mathrm{BNNT}+\mathrm{GNP}^{\prime}$ matrix, respectively. Both of these GFRP composites were significantly tougher than the GFRP composite with the unmodified epoxy matrix ('EP') which had a value of $G_{\mathrm{IC}}^{\mathrm{C}}=113 \pm 23 \mathrm{~J} \mathrm{~m}^{-2}$. The values of $G_{\mathrm{IC}}^{\mathrm{C}}$ for steady-state crack propagation in the GFRP composites were significantly greater than for crack initiation, as expected. Indeed, the relatively high values of $G_{\text {IC }}^{C}$ for steady-state crack propagation in the GFRP composites made using the epoxy nanocomposite matrices were especially noteworthy. However, whilst the hybrid combinations of nanofillers clearly resulted in higher mean values of toughness than for the neat, control bulk epoxy polymer ('EP') and the 'EP' GFRP composite, there were no consistent significant differences between the various types of nanofillers that were employed.

Further, for the mode I results the values of the coefficient of toughness transfer (CTT) from the bulk epoxy toughness to the interlaminar fracture toughness of the GFRP composite, with the corresponding epoxy as the matrix, were considered. However, there were no real significant differences in the values of CTT for the various epoxy materials, with values of CTT between about $0.6-0.7$ for crack initiation and 1.8-2.2 for crack propagation being determined. Further, as noted above, the GFRP composite with the hybrid 'EP + BNNS + $\mathrm{CNT}^{\prime}$ matrix had a somewhat low value of CTT of 0.65 , but gave the maximum value of $G_{\mathrm{IC}}^{\mathrm{C}}=181 \pm 48 \mathrm{~J} \mathrm{~m}^{-2}$. The value of CTT for mode I steady-state crack propagation was about two for all the various epoxy materials. This substantial increase in the value of CTT for crack propagation was suggested to be increased mainly due to fibre bridging, as was indeed experimentally observed to occur. Finally, it is interesting to note that, in this present work, no synergistic toughening effects were observed from using the hybrid combinations of 1D and 2D nanofillers compared to using the individual CNT and GNP nanofillers separately in the bulk epoxy polymers or in the matrices for the GFRP composites.

The mode II interlaminar fracture toughness, $G_{\text {IIC }}^{\mathrm{C}}$ at crack initiation for the GFRP composite with the neat epoxy matrix ('EP') had a value of $568 \pm 59 \mathrm{~J} \mathrm{~m}^{-2}$. A statistically significant increase in the value of $G_{\text {IIC }}^{\text {C }}$ for the GFRP composites was observed for all four nanocomposite matrices relative to the neat epoxy matrix ('EP'). The measured increases were about $49 \%, 59 \%, 37 \%$ and $42 \%$ for the 'EP + GNP', 'EP + CNT', hybrid 'EP + BNNS + $\mathrm{CNT}^{\prime}$ and hybrid 'EP + BNNT + GNP' matrices, respectively. This demonstrates the benefits of 
adding $1 \mathrm{D}$ and 2D nanofillers to an epoxy matrix in these fibre-reinforced composites.

\section{Acknowledgements}

Dr. Nadiim Domun much appreciates the Faculty of Science, Engineering and Computing (SEC) of Kingston University London and the National Physical Laboratory (NPL) for providing the financial support for his PhD study. Dr. Keith R. Paton acknowledges funding provided by the National Measurement System of the UK Department of Business, Enterprise and Industrial Strategy.

\section{Compliance with ethical standards}

Conflict of interest The authors declare no conflict of interest.

Open Access This article is licensed under a Creative Commons Attribution 4.0 International License, which permits use, sharing, adaptation, distribution and reproduction in any medium or format, as long as you give appropriate credit to the original author(s) and the source, provide a link to the Creative Commons licence, and indicate if changes were made. The images or other third party material in this article are included in the article's Creative Commons licence, unless indicated otherwise in a credit line to the material. If material is not included in the article's Creative Commons licence and your intended use is not permitted by statutory regulation or exceeds the permitted use, you will need to obtain permission directly from the copyright holder. To view a copy of this licence, visit http://creativecommons.org/licen ses/by $/ 4.0 /$.

\section{References}

[1] Kinloch A, Shaw SJ, Tod DA, Hunston DL (1983) Deformation and fracture behaviour of a rubber-toughened epoxy: 1. Microstructure and fracture studies. Polymer 24(10):1341-1354

[2] Gojny FH, Wichmann MHG, Fiedler B, Schulte K (2005) Influence of different carbon nanotubes on the mechanical properties of epoxy matrix composites - a comparative study. Compos Sci Technol 65:2300-2313

[3] Domun N, Hadavinia H, Zhang T, Sainsbury T, Liaghat GH, Vahid S (2015) Improving fracture toughness and strength of epoxy using nanomaterials - a review of current status. Nanoscale 7(23):10294-10329

[4] Johnsen B, Kinloch A, Mohammed R, Taylor A, Sprenger S (2007) Toughening mechanisms of nanoparticle-modified epoxy polymers. Polymer 48(2):530-541

[5] Chen J, Kinloch AJ, Sprenger S, Taylor AC (2013) The mechanical properties and toughening mechanisms of an epoxy polymer modified with polysiloxane-based core-shell particles. Polymer 54(16):4276-4289

[6] Domun N, Kaboglu C, Paton KR, Dear JP, Liu J, Blackman BRK, Liaghat GH, Hadavinia H (2019) Ballistic impact behaviour of glass fibre reinforced polymer composite with 1D/2D nanomodified epoxy matrices. Compos B 167:497-506

[7] Ladani RB, Ravindran AR, Wu S, Pingkarawat K, Kinloch AJ, Mouritz AP, Ritchie RO, Wang CH (2016) Multi-scale toughening of fibre composites using carbon nanofibres and z-pins. Compos Sci Technol 131:98-109

[8] Tang Y, Ye L, Zhang Z, Friedrich K (2013) Interlaminar fracture toughness and CAI strength of fibre-reinforced composites with nanoparticles - a review. Compos Sci Technol 86:26-37

[9] Kim J, Lee J (2016) Influence of interleaved films on the mechanical properties of carbon fiber fabric/polypropylene thermoplastic composites. Materials 9:344

[10] Kinloch A, Taylor AC (2006) The mechanical properties and fracture behaviour of epoxy-inorganic micro and nanocomposites. J Mater Sci. https://doi.org/10.1007/s10853-00 5-5472-0

[11] Pearson RA, Yee AF (1993) Toughening mechanisms in thermoplastic-modified epoxies: 1. Modification using poly(phenylene oxide). Polymer 34(17):3658-3670

[12] Fiedler B, Gojny FH, Wichmann MHG, Nolte MCM, Schulte K (2006) Fundamental aspects of nano-reinforced composites. Compos Sci Technol 66(16):3115-3125

[13] De Cicco D, Asaee Z, Taheri F (2017) Use of nanoparticles for enhancing the interlaminar properties of fiber-reinforced composites and adhesively bonded joints - a review. Nanomaterials 7:360

[14] Borowski E, Soliman E, Kandil U, Taha M (2015) Interlaminar fracture toughness of CFRP laminates incorporating multi-walled carbon nanotubes. Polymers 7:1020-1045

[15] Compston P, Jar P-YB, Davies P (1998) Matrix effect on the static and dynamic interlaminar fracture toughness of glassfibre marine composites. Compos B 29B:505-516

[16] Compston P, Jar P-YB, Burchill PJTK (2002) The transfer of matrix toughness to composite mode I interlaminar fracture toughness in glass-fibre/vinyl ester composites. Appl Compos Mater 9:291-314 
[17] Bradley WL (1989) Relationship of matrix toughness to interlaminar fracture toughness. In: Friedrich K (ed) Application of fracture mechanics to composite materials. Elsevier, Amsterdam, pp 159-187

[18] Bradley WL (1989) Understanding the translation of neat resin toughness into delamination toughness in composites. Key Eng Mater 37:161-198

[19] Jordan WM, Bradley WL, Moulton RJ (1989) Relating resin mechanical properties to composite delamination fracture toughness. J Compos Mater 23:923-943

[20] Hunston DL, Moulton RJ, Johnston NJ, Bascom WD (1987) Matrix resin effects in composite delamination mode I fracture aspects. In: Johnston NJ (ed) Toughened Composites, ASTM STP 937. American Society for Testing and Materials, Philadelphia, pp 74-94

[21] Bascom WD, Cottington RL (1976) Effect of temperature on the adhesive fracture behavior of an elastomer-epoxy resin. J Adhes 7:333-346

[22] Zeng Y, Liu H-Y, Mai Y-W, Du X-S (2012) Improving interlaminar fracture toughness of carbon fibre/epoxy laminates by incorporation of nano-particles. Compos B 43:90-94

[23] Carolan D, Ivankovic A, Kinloch AJ, Sprenger S, Taylor AC (2017) Toughened carbon fibre-reinforced polymer composites with nanoparticle-modified epoxy matrices. J Mater Sci 52(3):1767-1788. https://doi.org/10.1007/s10853-016-0 468-5

[24] Hsieh TH, Kinloch AJ, Masania K, Lee JS, Taylor AC, Sprenger S (2010) The toughness of epoxy polymers and fibre composites modified with rubber microparticles and silica nanoparticles. J Mater Sci 45(5):1193-1210. https://d oi.org/10.1007/s10853-009-4064-9

[25] Kinloch AJ, Masania K, Sprenger S, Taylor AC (2009) The fracture of nanosilica and rubber toughened epoxy fibre composites. In: Proceedings of ICCM-17 17th international conference on composite materials, Edinburgh, UK

[26] Becker O, Varley RJ, Simon GP (2003) Use of layered silicates to supplementarily toughen high performance epoxycarbon fiber composites. J Mater Sci Lett 22:1411-1414

[27] Siddiqui NA, Woo RS, Kim J-K, Leung CCK, Munir A (2007) Mode I interlaminar fracture behavior and mechanical properties of CFRPs with nanoclay-filled epoxy matrix. Compos A 38(2):449-460

[28] Ashrafi B, Guan J, Mirjalili V, Zhang Y et al (2011) Enhancement of mechanical performance of epoxy/carbon fiber laminate composites using single-walled carbon nanotubes. Compos Sci Technol 71:1569-1578

[29] Quan D, Urdániz JL, Ivanković A (2018) Enhancing mode-I and mode-II fracture toughness of epoxy and carbon fibre reinforced epoxy composites using multi-walled carbon nanotubes. Mater Des 143:81-92

[30] Domun N, Paton KR, Hadavinia H, Sainsbury T, Zhang T, Mohamud H (2017) Enhancement of fracture toughness of epoxy nanocomposites by combining nanotubes and nanosheets as fillers. Materials 10(10):1179

[31] Domun N, Hadavinia H, Zhang T, Liaghat GH, Vahid S, Paton K, Spacie C, Sainsbury T (2017) Improving the fracture toughness properties of epoxy using graphene nanoplatelets at low filler content. Nanocomposites 3(3):85-96

[32] ASTM D3039/D3039M-17 (2017) Standard test method for tensile properties of polymer matrix composite materials composite materials

[33] ASTM D3518/D3518M-13 (2013) Standard test method for in-plane shear response of polymer matrix composite materials by tensile test of a $\pm 45^{\circ}$ laminate

[34] ISO 15024 (2016) Fibre-reinforced plastic composites-determination of mode I interlaminar fracture toughness, GIC, for unidirectionally reinforced materials

[35] Williams JG (1989) End correction for orthotropic DCB specimens. Compos Sci Technol 35(4):367-376

[36] Hashemi SS, Kinloch AJ, Williams JG (1989) Corrections needed in double cantilever beam tests for assessing the interlaminar failure of fibre-composites. J Mater Sci Lett $8: 125-129$

[37] BS 7991:2001 (2001) Determination of the mode I adhesive fracture energy, GIC, of structural adhesives using the double cantilever beam (DCB) and tapered double cantilever beam (TDCB) specimens

[38] Williams JG (1987) Large displacement and end block effects in the DCB interlaminar test in modes I \& II. J Compos Mater 21:330-347

[39] de Moura MFSF, de Morais AB (2008) Equivalent crack based analyses of ENF and ELS tests. Eng Fract Mech 75:2584-2596

[40] Hine PJ, Brew B, Duckett RA, Ward IM (1989) Failure mechanisms in continuous carbon-fibre reinforced PEEK composites. Compos Sci Technol 35:31-51

[41] Sacchetti F, Grouve WJB, Warnet LL, Villega IF (2018) Interlaminar fracture toughness of $5 \mathrm{HS}$ carbon/PEEK laminates. A comparison between DCB, ELS and mandrel peel tests. Polym Test 66:13-23

Publisher's Note Springer Nature remains neutral with regard to jurisdictional claims in published maps and institutional affiliations. 